\title{
Performance Evaluation of Fluorescence and Photostability of Coumarin Disperse Yellow 82
}

\author{
Aba Akebi Atta-Eyison \\ Department of Industrial and Health Sciences, Takoradi Technical University, Takoradi, Ghana \\ Email: akebi80@yahoo.co.uk, aba.atta-eyison@ttu.edu.gh
}

How to cite this paper: Atta-Eyison, A.A. (2020) Performance Evaluation of Fluorescence and Photostability of Coumarin Disperse Yellow 82. Journal of Materials Science and Chemical Engineering, 8, 11-19. https://doi.org/10.4236/msce.2020.81002

Received: November 28, 2019

Accepted: December 31, 2019

Published: January 3, 2020

Copyright $\odot 2020$ by author(s) and Scientific Research Publishing Inc. This work is licensed under the Creative Commons Attribution International License (CC BY 4.0).

http://creativecommons.org/licenses/by/4.0/

(c) (i) Open Access

\begin{abstract}
This paper describes some significant fluorescent and photostability properties of Coumarin Disperse Yellow 82. The study aims at spectrophotometric colour measurements on fluorescence of Coumarin Disperse Yellow 82. Spectral parameters such as relative strength percentage and reflectance with different dye concentrations performance on polyester and polyester/cotton substrates were assessed. Light fastness property was also evaluated. Evaluation of photodegradation quantum yield of the dye in methanol, ethanol and $\mathrm{N}, \mathrm{N}$-dimethylformamide (DMF) under aerobic and anaerobic conditions have also been investigated. The relative strength, reflectance and light fastness of dyed polyester for the different dye concentrations were proven to be better in comparison to dyed polyester/cotton blend. The photodegradation quantum yield of dye in methanol, ethanol and DMF solutions under anaerobic condition showed higher dye photodegradation quantum in DMF for the various concentrations of dye used. Under aerobic condition irradiation under nitrogen atmosphere attained higher degradation whereas the presence of air reduced degradation.
\end{abstract}

\section{Keywords}

Disperse Dye, Relative Strength, Reflectance, Light Fastness, Quantum Yield

\section{Introduction}

Fluorescent dyes are used in diverse fields of study such as in biochemical investigations, medical diagnoses, construction of photoelectric cells, lasers and solar batteries [1] [2]. The application of fluorescent dyes to synthetic fibres has gained relevance in textiles regarding aesthetic and functional requirement [3]. These dyes when used on synthetic fibres produce fluorescence under solar and UV radiation. The remarkable brilliant colours resulting from the radiance of 
emitted fluorescence of fluorescent synthetic fibres textiles have made it attractive for various applications such as safety wear, sportswear, leisure wear and work wear [4] [5]. The major consumption of fluorescent dyes in textiles is for the dyeing synthetic fibres especially polyester. Disperse dyes are most fluorescent among textile dyes and most suitably used on polyesters [1] [6] [7].

The classification of disperse dyes by chromogen is significant for forensic analysts. Azo and anthraquinone disperse dyes are the main classes of disperse dyes in the market with the highest possibility of being subjected to forensic investigations [8]. Coumarin dyes have also gained recognition as one of the greatest commercially significant groups of fluorescent dyes having yellow with a green fluorescence as most commercial products. Fluorescent coumarins absorb and emit mostly in the visible region of the electromagnetic spectrum [9]. This group of dyes offers important disperse dyes which include C.I. Disperse Reds 277 (5a) and 374 (5b) and C.I. Disperse Yellows 82 (2a), 184 (2d), 186 (3) and 232 (2d). Coumarin dyes produce excellent fluorescent greenish-yellow shades on synthetic fibers, especially polyester. Analysis of fluorescent textile fibers involves measurement of physical and optical properties which includes visual colour matching, UV/visible spectral comparisons and infrared (IR) spectroscopy. These techniques are non-destructive, and effective in discriminating fiber evidence. Various microscopic, spectroscopic and chromatographic methods have also been used to analyse many fluorescence dyes based on their fluorescent characteristics due to their ability to provide substantial information in forensic analyses. Some of these methods include microspectrophotometry [10] [11], Raman spectroscopy [12] [13] [14] infrared matrix-assisted laser desorption electrospray, liquid chromatography (HPLC) with different detectors [15] [16] [17] [18] thin liquid chromatography (TLC) [19] and capillary electrophoresis with a DAD or MS detector [20] [21] [22]. The primary objective of this study was to investigate the fluorescent and photostabily property of Coumarin Disperse Yellow 82. In the first step of this study, fluorescent properties such as fluorescent emission, relative strength and percentage reflectance of the dye were assessed. Light fastness test was also evaluated. Finally, photodegradation quantum yield of the dye in methanol, ethanol and N,N-dimethylformamide (DMF) solutions under aerobic and anaerobic conditions was investigated.

\section{Experimental}

Coumarin Disperse Yellow 82 used for this study was obtained from Classic Dyestuffs Inc (Figure 1). Spectrophotometric absorption and forensic spectrophotometric tests were recorded. Maximum absorbance was recorded as $430 \mathrm{~nm}$ which is typical of yellow dyes. A mirror image of fluorescent emission of dye was obtained (Figure 2). The purity of the dye was checked by HPLC. A distinct sharp peak with a retention times of 16.65 min was observed when the detector was set at $430 \mathrm{~nm}$ (Figure 3). Sample solution with different concentrations was prepared $(1-35 \mathrm{~g} / \mathrm{L})$ to evaluate their photodegradation quantum yield. The dye solutions at different concentrations in methanol, ethanol and DMF were faded 
<smiles>CCN(CC)c1ccc2oc(=O)c(-c3nc4ccccc4[nH]3)cc2c1</smiles>

Figure 1. Coumarin Disperse Yellow 82.

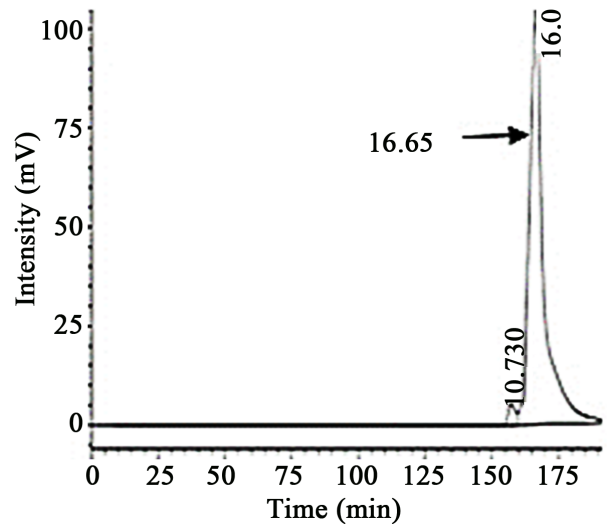

Figure 2. HPLC chromatogram for Coumarin Disperse Yellow 82 dye with a concentration of $35 \mathrm{~g} / \mathrm{L}$. Conditions: wavelength $=430 \mathrm{~nm}$, temperature $25^{\circ} \mathrm{C} \pm 2^{\circ} \mathrm{C}, \mathrm{pH} 6.9$, mobile phase [acetonitrile:water $(80: 20, \mathrm{v} / \mathrm{v})]$, flow rate $=0.5 \mathrm{ml} / \mathrm{min}$.

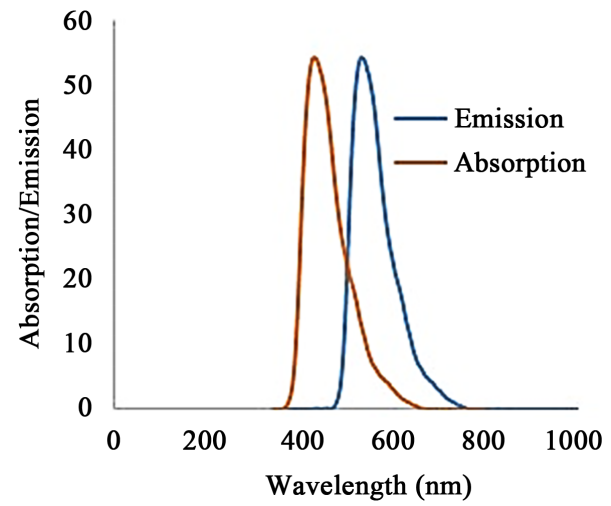

Figure 3. Absorption and emission spectra of a Coumarin Disperse Yellow 82.

at $300 \mathrm{~nm}$ in a six interchangeable light source Rayonett photolytic reactor RPR-100 under aerobic and anaerobic conditions. Aerobic conditions were attained by passing dry air or nitrogen through the solutions for $40 \mathrm{~min}$ before irradiation at $300 \mathrm{~nm}$. The extent of fading was determined spectrophotometrically using Jenway 7315 Spectrophotometer. The intensity of the photolysis light source was determined using uranyl oxalate actinometer prepared by placing a treated solution of uranyl sulphate with excess oxalic acid in quartz vessel under UV light. The number of quanta absorbed by the system per second was calculated by comparing the amount of oxalate molecules decomposed with the established quantum yields of the decomposition of oxalate molecules per quantum absorbed $\left(Q_{300}=0.57\right)$. The quantum yield of dye fading was calculated from the number of dye molecules decomposed and the number of quanta absorbed over 
the same time for the various concentrations. Polyester and polyester/cotton fabrics $(60 / 40)$ were dyed at varying concentrations to determine their reflectance and light fastness property. Light fastness was measured on a Hanau Xenotest Grey Scale apparatus which correspond to British Standards with a rating of 1 to 5 where rating " 5 " and " 1 " describe excellent and very poor respectively. Reflectance values and curves of the dyed fabrics were determined in the visible portion of the spectrum $(400-700 \mathrm{~nm})$ using a reflectance spectrophotometer (ocean optics USB 2000) with a detector, LS-1 tungsten-Halogen lamp and the standard illuminant was D65 with $10^{\circ}$ observer. Four measurements were taken for each folded samples and their average was taken for the analysis of each result. The colour strength values (\%) of samples were determined in comparison to the deepest dyeing ( $35 \mathrm{~g} / \mathrm{L}$ dyed sample) as $100 \%$ colour strength by using the following equation:

$$
\% \text { Strength }=\frac{K / S_{(\text {sample })}}{K / S_{(\text {standard })}} \times 100
$$

where $K / S$ is the absorption function and can be computed using the equation:

$$
K / S=(1-R)^{2} / 2 R \quad \text { (Kubelka-Munk equation) }
$$

$R=$ minimum reflectance value at a wavelength of maximum absorption.

\section{Results}

\subsection{Reflectance Analysis}

Significant relative strength values were measured from the dyed fabrics. The relative strength of dyed polyester fabric samples was however higher than dyed polyester/cotton fabrics with increasing concentration (Figure 4).

The minimum and maximum reflectance of the luminous yellow shade was found at $450 \mathrm{~nm}$ and $520 \mathrm{~nm}$ respectively from the emission spectra (Figure 5(a), Figure 5(b)) for both dyed fabrics. A wavelength of minimum reflectance of $8.5 \%-23 \%$ and $8.5 \%-26 \%$ and maximum reflectance of $117 \%-175 \%$ and $117 \%-142.5 \%$ was observed at $450 \mathrm{~nm}$ and $520 \mathrm{~nm}$ for polyester and polyester/cotton fabric respectively. Dyed polyester fabric samples showed greater reflectance (\%) and colour strength than dyed polyester/cotton fabric samples. The higher reflectance and relative strength were possibly due to higher dye fibre interaction between dye and polyester. Disperse dyes are specially formulated non-ionic aromatic hydrophobic compounds and hence exhibit good bonding ability on polyester due to the high crystallinity and hydrophobicity of polyester. The hydrophilic ionic nature of cotton does not make it suitable to be dyed by disperse dyes [23] [24]. Hence interaction between dye and polyester/cotton is minimal.

\subsection{Evaluation of Light Fastness of Dyed Samples}

Light fastness exceptionally test resulted in strong fading for polyester/cotton fabric at highest concentration. The extent of fading in dyed polyester was however 


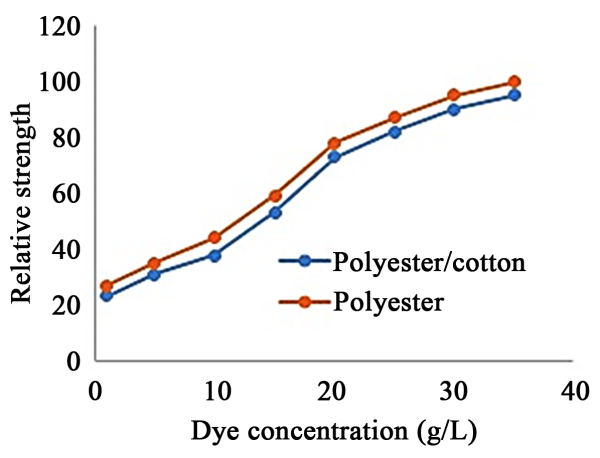

Figure 4. Percentage relative strength of Coumarin Disperse Yellow 82 on polyester and polyester/cotton fabric.

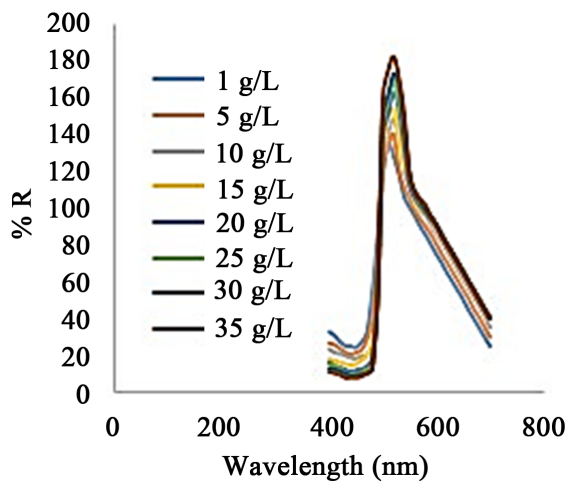

(a)

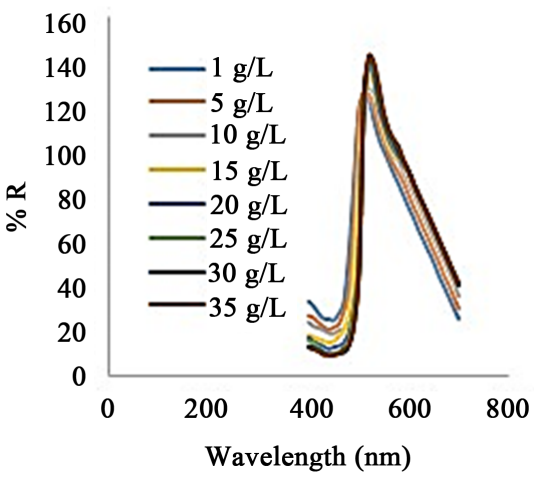

(b)

Figure 5. Reflectance curve of Coumarin Disperse Yellow 82 (a) dyed polyester and (b) dyed polyester/cotton.

minimal. From Figure 6, polyester fabrics dyed with lesser dye concentrations (1 - $15 \mathrm{~g} / \mathrm{L}$ ) showed better light fastness value of 4.5. Highest light fastness value of 4 was observed for dyed polyester/cotton fabric with the concentration range of 1 to $10 \mathrm{~g} / \mathrm{L}$. Higher fading recorded for dyed polyester/cotton fabrics is possibly due to the inability of the dye to bond to cotton.

\subsection{Evaluation of Quantum Yield}

The photodegradation of dye in methanol, ethanol and DMF solutions at 300 $\mathrm{nm}$ under anaerobic conditions is shown in Figure 7. Methanol and ethanol showed comparable lower dye photodegradation quantum for the various concentrations of dye used compared to that of DMF. The degradation of the Coumarin Disperse Yellow 82 was therefore enhanced in DMF but retarded in methanol and ethanol.

Investigations under aerobic conditions showed that the photostability of Coumarin Disperse Yellow 82 strongly depends on the presence of air (Figure 8). For the various dye concentration after 90 min irradiation in methanol only $8 \%-22 \%$ degradation was achieved, whereas in the presence of nitrogen, $27 \%$ $38 \%$ destruction occurred within $2 \mathrm{hrs}$. Similar results were obtained for photolysis experiments conducted in ethanol. Dye showed only $9 \%-24 \%$ degradation 


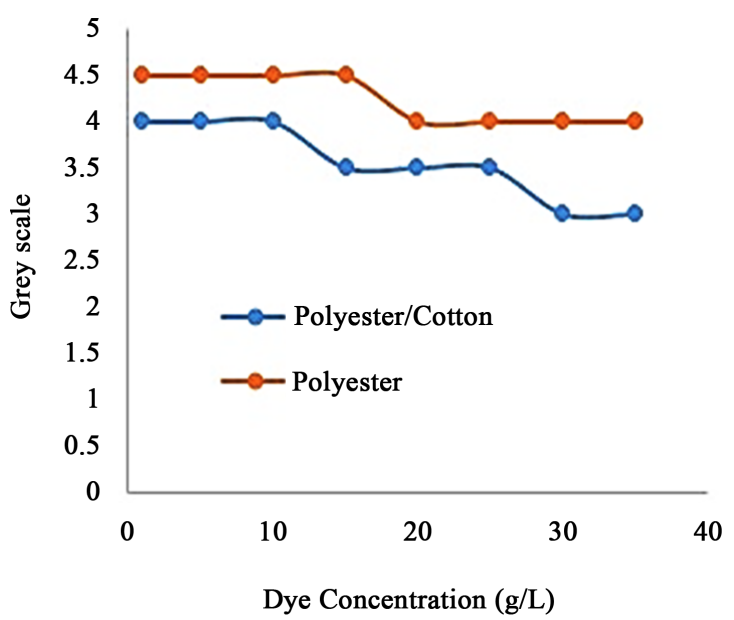

Figure 6. Light fastness of dyed polyester and polyester/cotton blend.

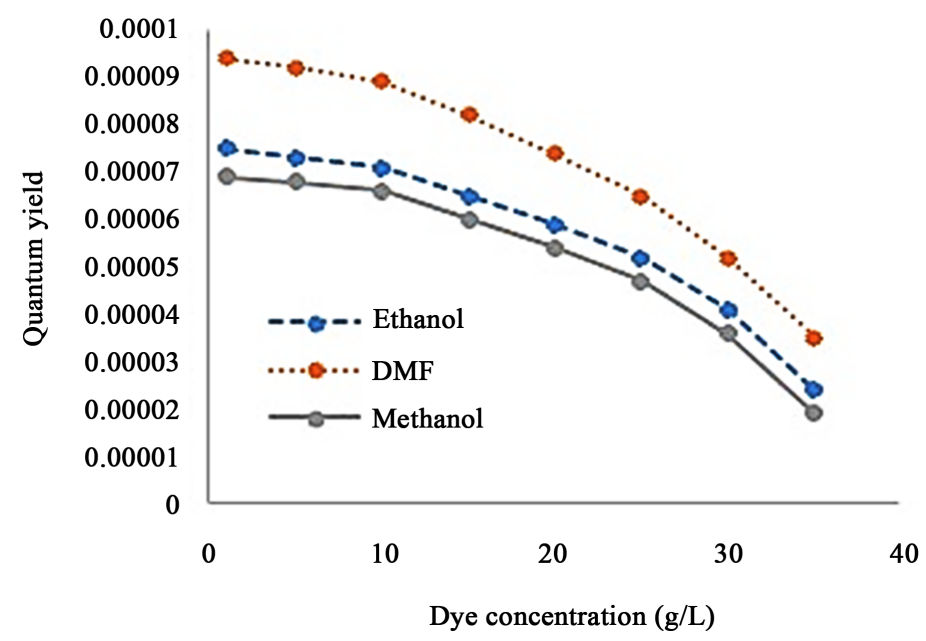

Figure 7. Photodegradation quantum yield of dye in methanol, ethanol and DMF at varying concentrations under anaerobic condition.

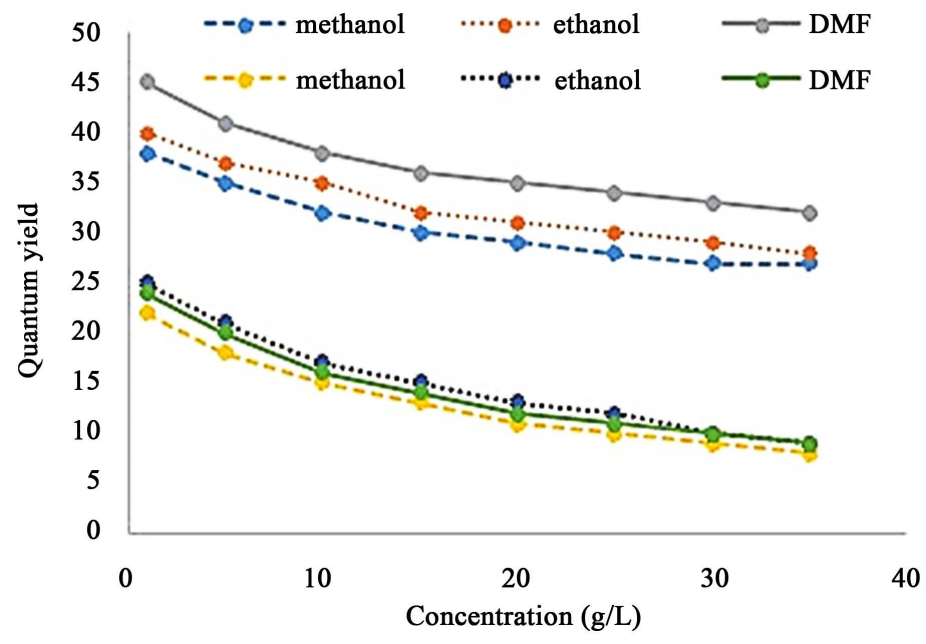

Figure 8. Photodegradation quantum yield of dye in methanol, ethanol and DMF at varying concentrations under aerobic condition. 
after 90 min irradiation in the presence of air, whereas $2 \mathrm{hrs}$ irradiation in the presence of nitrogen caused some $28 \%-40 \%$ destruction. The results of photolysis in DMF was higher in comparison with the other two solvents. The presence of air however strongly limited the extent of degradation of the dye concentration. The various dye concentrations when irradiated in DMF under nitrogen atmosphere attained 32\% - 45\% degradation, whereas the presence of air reduced this to $9 \%-25 \%$ after $2 \mathrm{hrs}$ irradiation.

An attempt was made to isolate and define the structure of the major photolysis products of the dye under nitrogen using GCMS. Two major identical materials were found among the many degradation products for the various solvent. GCMS analysis revealed that the dye in the various solvents degraded similarly, possibly through abstraction of the heterocyclic residue probably through a reductive process [25]. The presence of peaks characterized by $\mathrm{m} / \mathrm{z} 275$ and $\mathrm{m} / \mathrm{z}$ 246 in GCMS were the two major degradation products of the dye. A difference of the molecular mass of the two major degradation products corresponds to the loss of an ethyl group. Although the photodegradation of the dye in methanol, ethanol and DMF generated the same products, the three solvents may possibly differ in the mechanism of their reduction; two possible photoreduction might be considered. The excited dye molecule may engage in hydrogen abstraction or in electron transfer from the environment, followed by protonation of the radical anion formed. Hydrogen abstraction however dominates, especially under $300 \mathrm{~nm}$ irradiation [25] [26] according to the literature.

\section{Conclusion}

The relative strength, reflectance and light fastness of dyed polyester for the various dye concentration was proven to be better than dyed polyester/cotton. The photodegradation quantum yield of dye in methanol, ethanol and DMF solutions under anaerobic condition showed higher dye photodegradation quantum in DMF for the various concentrations of dye used. Under aerobic condition irradiation under nitrogen atmosphere attained higher degradation whereas the presence of air reduced degradation. In accordance with the estimated degradation quantum yields of the examined dye in methanol, ethanol and DMF it can be concluded that alcohol is slightly better than DMF as a model solvent for the prediction of the photostability of Coumarin Disperse Yellow 82 on polyester.

\section{Conflicts of Interest}

The author declared no conflicts of interest regarding the publication of this paper.

\section{References}

[1] Hamdaoui, M., Lanouar, A. and Halaoua, S. (2015) Study of Fluorescent Dyeing Process and Influence of Mixture Dyes on High-Visibility. Journal of Engineered Fibers and Fabrics, 10, 89-96. https://doi.org/10.1177/155892501501000109

[2] Licudine, J.A., McQuate, G.T., Cunningham, R.T., Liquido, N.J., Li, Q.X. and Ma- 
nag, P. (2002) Efficacy and Residues of Phloxine B and Uranine for the Suppression of Mediterranean Fruit Fly in Coffee Fields. Pest Management Science, 58, 38-44. https://doi.org/10.1002/ps.418

[3] Farzana, N. (2015) Fluorescent Disperse Dyes: Reflectance Spectra, Relative Strength and Performance Evaluation of Coumarin Class on Polyester/Cotton Blended Fabric. International Journal of Research in Engineering and Technology, 4, 488-494.

[4] Christie, R.M. (2011) Handbook of Textile and Industrial Dyeing. Heriot-Watt University, Woodhead Publishing Ltd., Cambridge.

[5] Szuster, L., Kaźmierska, M. and Król, I. (2004) Fluorescent Dyes Destined for Dyeing High-Visibility Polyester Textile Products. Fibres \& Textiles in Eastern Europe, 12,45 .

[6] Broadbent, A.D. (2001) Basic Principles of Textile Coloration. SDC, Bradford.

[7] Koh, J. (2011) Dyeing with Disperse Dyes. In: Hauser, P., Ed., Textile Dyeing, IntechOpen, London, 196-197.

http://www.intechopen.com/books/textile-dyeing/dyeing-with-disperse-dyes https://doi.org/10.5772/20458

[8] Smigiel-Kaminska, D., Pospiech, J., Makowska, J., Stepnowski, P., JolantaWas-Gubała and Kumirska, J. (2019) The Identification of Polyester Fibers Dyed with Disperse Dyes for Forensic Purposes. Molecules, 24, 613. https://doi.org/10.3390/molecules24030613

[9] Jain, P.K. and Joshi, H. (2012) Coumarin: Chemical and Pharmacological Profile. Journal of Applied Pharmaceutical Science, 2, 236-240.

[10] Was-Gubała, J. and Starczak, R. (2015) UV-Vis Microspectrophotometry as a Method of Differentiation between Cotton Fiber Evidence Coloured with Reactive Dyes. Spectrochimica Acta Part A: Molecular and Biomolecular Spectroscopy, 142, 118-125. https://doi.org/10.1016/j.saa.2015.01.116

[11] Reichard, E.J., Bartick, E.G., Morgan, S.L. and Goodpaster, J.V. (2017) Microspectrophotometric Analysis of Yellow Polyester Fiber Dye Loadings with Chemometric Techniques. Analytical Chemistry, 3, 21-27. https://doi.org/10.1016/j.forc.2016.11.001

[12] Buzzini, P. and Massonnet, G. (2015) The Analysis of Colored Acrylic, Cotton, and Wool Textile Fibers Using Micro-Raman Spectroscopy. Journal of Forensic Sciences, 60, 712-720. https://doi.org/10.1111/1556-4029.12654

[13] Was-Gubała, J. and Machnowski, W. (2016) Application of Raman Spectroscopy for Differentiation among Cotton and Viscose Fibers Dyed with Several Dye Classes. Spectroscopy Letters, 47, 527-535. https://doi.org/10.1080/00387010.2013.820760

[14] Zaffino, C., Bruni, S., Guglielmi, V. and De Luca, E. (2014) Fourier-Transform Surface-Enhanced Raman Spectroscopy (FT-SERS) Applied to the Identification of Natural Dyes in Textile Fibers: An Extractionless Approach to the Analysis. Journal of Raman Spectroscopy, 45, 211-218. https://doi.org/10.1002/jrs.4443

[15] Carey, A., Rodewijk, N., Xu, X. and Van Der Weerd, J. (2013) Identification of Dyes on Single Textile Fibers by HPLC-DAD-MS. Analytical Chemistry, 85, 11335-11343. https://doi.org/10.1021/ac402173e

[16] Kato, T., Suzuki, Y. and Handa, M. (2016) Extraction and Analysis of Disperse Dyes from Colored Polyester Single Fibers Using Liquid Chromatography/Linear Ion Trap Tandem Mass Spectrometry. Analytical Sciences, 32, 1019-1022. https://doi.org/10.2116/analsci.32.1019

[17] Zhou, Y., Du, Z. and Zhang, Y. (2014) Simultaneous Determination of 17 Disperse 
Dyes in Textile by Ultra-High Performance Supercritical Fluid Chromatography Combined with Tandem Mass Spectrometry. Talanta, 127, 108-115. https://doi.org/10.1016/j.talanta.2014.03.055

[18] Hu, C., Zhu, J., Mei, H., Shi, H., Guo, H., Zhang, G., Wang, P., Lu, L. and Zheng, X. (2018) A Sensitive HPLC-MS/MS Method for the Analysis of Fiber Dyes. Forensic Chemistry, 11, 1-6. https://doi.org/10.1016/j.forc.2018.08.001

[19] Houck, M.M. (2009) Identyfication of Textile Fibers. Woodhead Publishing, Cambridge. https://doi.org/10.1533/9781845695651

[20] Morgan, S., Vann, B., Baguley, B. and Stefan, A. (2007) Advances in Discrimination of Dyed Textile Fibers Using Capillary Electrophoresis/Mass Spectrometry. Proceedings of the Trace Evidence Symposium, Clearwater Beach, 16 August 2007, 6-41.

[21] Stefan, A.R., Dockery, C.R., Baguley, B.M., Vann, B.C., Nieuwland, A.A., Hendrix, J.E. and Morgan, S.L. (2009) Microextraction, Capillary Electrophoresis, and Mass Spectrometry for Forensic Analysis of Azo and Methane Basic Dyes from Acrylic Fibers. Analytical and Bioanalytical Chemistry, 394, 2087-2094. https://doi.org/10.1007/s00216-009-2897-3

[22] Farah, S., Kunduru, K.R., Tsach, T., Bentolila, A. and Domb, A.J. (2015) Forensic Comparison of Synthetic Fibers. Polymers for Advanced Technologies, 26, 785-796. https://doi.org/10.1002/pat.3540

[23] Joonseok, K., Hoegyeong, K., Jieun, L. and Minyoung, E. (2009) Dyeing and Fastness Properties of Phthalimide-Based Alkali-Clearable Azo Disperse Dyes on Poly(ethylene terephthalate). Coloration Technology, 125, 322-327. https://doi.org/10.1111/j.1478-4408.2009.00213.x

[24] Aspland, J.R. (1992) Disperse Dyes and Their Application to Polyester. Textile Colour and Chemical, 24, 18-23.

[25] Sokoowska, J., Czajkowski, W. and Podsiady, R. (2001) The Photostability of Some Fluorescent Disperse Dyes Derivatives of Coumarin. Dyes and Pigments, 49, 187-191. https://doi.org/10.1016/S0143-7208(01)00018-3

[26] Muldoon, M.J., McLean, A.J., Gordon, C.M. and Dunkin, I.R. (2001) Hydrogen Abstraction from Ionic Liquids by Benzophenone Triplet Excited States. Chemical Communications, 1, 2364-2365. https://doi.org/10.1039/b107730a 